\title{
Tissue microarray analysis indicates hedgehog signaling as a potential prognostic factor in intermediate-risk prostate cancer
}

Annelies Gonnissen ${ }^{1,2+}$, Sofie Isebaert ${ }^{1,2^{*}}$, Christiaan Perneel ${ }^{3}$, Chad M. McKee ${ }^{4}$, Clare Verrill ${ }^{5}$, Richard J. Bryant ${ }^{5}$, Filip Van Utterbeeck ${ }^{3}$, Evelyne Lerut ${ }^{6}$, Karin Haustermans ${ }^{1,2}$ and Ruth J. Muschel ${ }^{4}$

\begin{abstract}
Background: Prostate cancer ( $\mathrm{PCa}$ ) is a heterogeneous disease with a variable natural history, genetics, and treatment outcome. The Hedgehog $(\mathrm{Hh})$ signaling pathway is increasingly recognized as being potentially important for the development and progression of PCa. In this retrospective study, we compared the activation status of the Hh signaling pathway between benign and tumor tissue, and evaluated the clinical significance of Hh signaling in PCa.

Methods: In this tissue microarray (TMA) study, the protein expression of several Hh signaling components and Hh target proteins, along with microvessel density, were compared between benign $(n=64)$ and malignant ( $n=170$ ) prostate tissue, and correlated with PCa clinicopathological characteristics and biochemical recurrence (BCR).

Results: The Hh signaling pathway appeared to be more active in PCa than in benign prostate tissue, as demonstrated by lower expression of the negative regulators PTCH1 and GLI3 in the tumor tissue compared to benign. In addition, high epithelial GLI2 expression correlated with higher pathological Gleason score. Overall, higher epithelial GLI3 expression in the tumor was shown to be an independent marker of a favorable prognosis.
\end{abstract}

Conclusion: Hh signaling activation might reflect aggressive tumoral behavior, since high epithelial GLI2 expression positively correlates with a higher pathological Gleason score. Moreover, higher epithelial GLI3 expression is an independent marker of a more favorable prognosis.

Keywords: Hedgehog pathway, Prostate cancer, Tissue microarray, Biochemical recurrence

\section{Background}

The Hedgehog $(\mathrm{Hh})$ signaling pathway is an important developmental signaling pathway regulating cellular proliferation and differentiation, and tissue polarity, in several tissue types including the prostate gland during embryogenesis [1-3]. In normal adult tissues this pathway appears to be relatively quiescent, but it is important for maintenance of stem cell populations and for repair and regeneration following tissue damage

\footnotetext{
* Correspondence: sofie.isebaert@uzleuven.be

${ }^{\dagger}$ Equal contributors

'Department of Oncology, Laboratory of Experimental Radiotherapy, KU Leuven - University of Leuven, KU Leuven Campus Gasthuisberg, Herestraat 49, box 815, 3000 Leuven, Belgium

${ }^{2}$ Department of Radiation Oncology, University Hospitals Leuven, Leuven, Belgium Full list of author information is available at the end of the article
}

$[2,4]$. Reactivation of Hh signaling has recently been observed in multiple tumor types including prostate cancer (PCa) $[2,5]$.

Activation of the $\mathrm{Hh}$ signaling cascade is triggered by binding of a ligand such as Sonic Hedgehog (SHH) to the inhibitory receptor Patched 1 (PTCH1), which acts to alleviate the repression of Smoothened (SMO). In turn, SMO activates the downstream effectors of the $\mathrm{Hh}$ signaling cascade, including the Glioma-associated oncogene (GLI) transcription factors through inhibition of Suppressor of Fused (SUFU), which is a key negative regulator of Hh signaling [6,7]. The GLI transcription factor family consists of three members, with GLI1 being the principle transcriptional activator. GLI2 has been shown to possess dual functionality, 
whilst GLI3 is primarily considered to be a Hh signaling repressor [8-10] (Fig. 1).

In this study the expression of Hh signaling components in benign and malignant prostate tissue was compared. PCa is a heterogeneous malignancy with a variable natural history, and the TMA cohort in this analysis is composed predominantly of intermediate-risk Gleason Sum score (GS) $7 \mathrm{PCa}$ cases. It is a particular clinical challenge to tailor appropriate management of intermediate-risk $\mathrm{PCa}$, and there is a limited number of clinically applicable biomarkers with which to riskstratify intermediate-risk $\mathrm{PCa}$ according to its potential indolent or aggressive behaviour [11, 12]. Hh pathway protein expression was investigated in order to determine whether this has potential prognostic value in this category of PCa cases.

\section{Methods}

\section{Tissue microarray}

Tissue microarrays (TMAs) were constructed from formalin-fixed paraffin-embedded (FFPE) radical prostatectomy specimens from $170 \mathrm{PCa}$ patients, and from trans-urethral resection of the prostate (TURP) samples from 64 patients with benign prostatic hyperplasia (BPH). The TMA consisted of a single tissue core for each of the 234 patients.

TMA sections were obtained from the Oxford Centre for Histopathology Research, Oxford University Hospitals NHS Foundation Trust, Oxford, UK. The TMA contained patient samples from Oxford and was built under the approval of the Oxford Radcliffe Biobank Ethics Committee (reference number 09/H0606/5 + 5). The study itself was approved by the ethics committee of KU Leuven, Leuven, Belgium (reference number S55726).

\section{Immunohistochemistry}

Immunohistochemistry was performed using primary antibodies against SHH (1/50, Abcam ab53281), PTCH1 (1/300, Santa Cruz sc-6147), SMO (1/100, Abcam, ab72130), SUFU (1/100, Santa Cruz sc-28,847), GLI1 (1/ 50, Santa-Cruz sc-20,687), GLI2 (1/1000, Rockland 600401-845), GLI3 (1/50, R\&D AF3690), SNAIL (1/50, R\&D, AF3639), SNAI3 (1/50, Novus Biologicals, NBP190661), CYCLIND1 (Dako, M364229) and CD31 (Dako, IR610 Clone JC70A). After incubation with the appropriate secondary antibody (Vector Laboratories), antigen presence was revealed with 3.3'-diaminobenzidine (DAB) substrate (Vector Laboratories, ImmPACT DAB, SK4105) and slides were counterstained with hematoxylin. Control TURP resection specimens were used to validate the specificity of the primary antibodies, which was histopathologically assessed based on the expected subcellular localization of each protein and a lack of nonspecific background staining. For the validation of Snail expression, blood vessel staining was used as an internal positive control. To exclude any nonspecific staining of the secondary antibodies, negative controls were performed without the addition of any primary antibody.

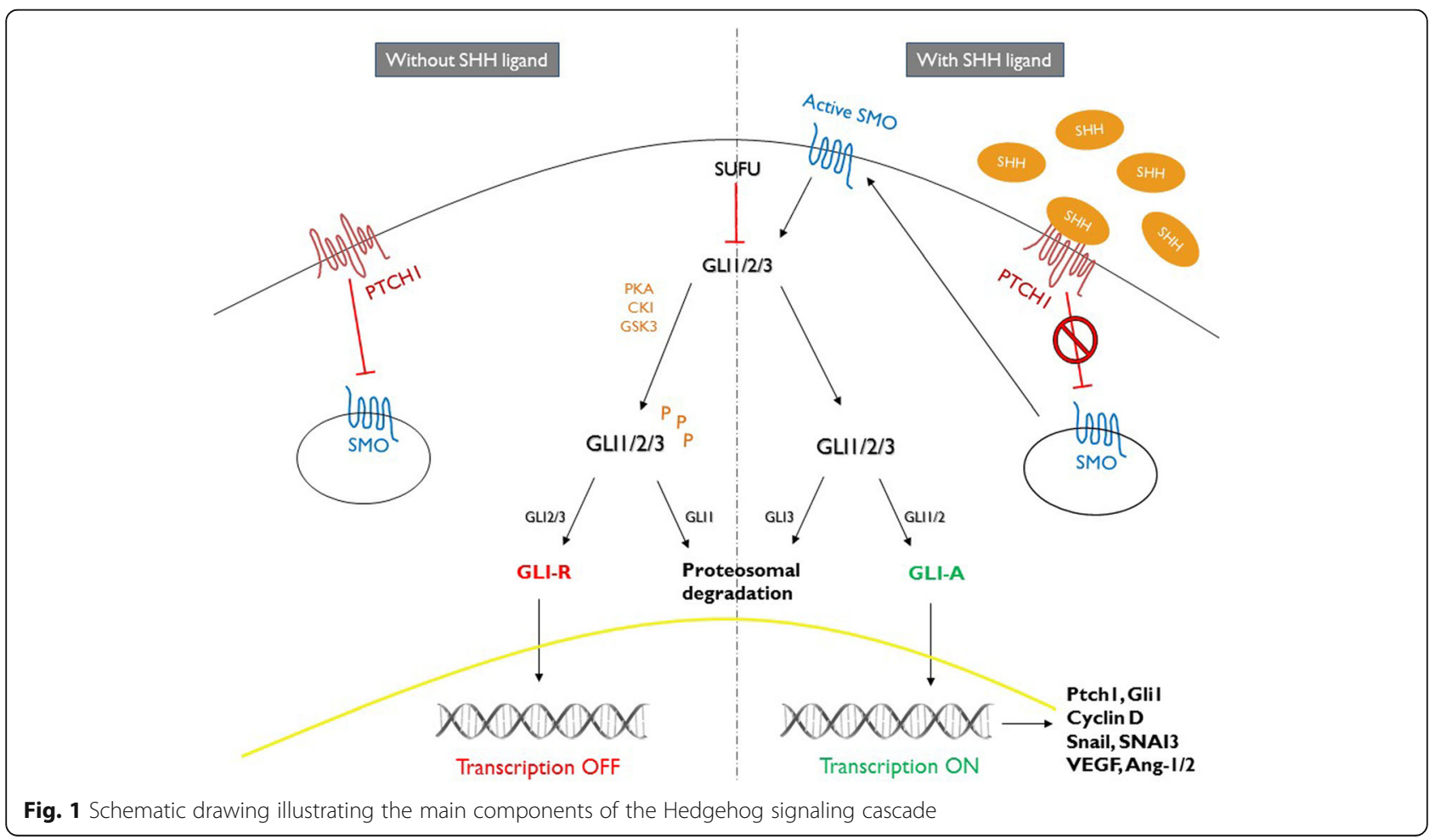




\section{Immunohistochemistry scoring}

Two independent researchers performed evaluation of the immunohistochemical staining for each protein, and each researcher was blinded to clinicopathological and outcome data. The percentage of stained cells (0-100\%) and the staining intensity $(0=$ negative, 1 = weak, 2 = moderate, 3 = strong) were assessed both in the epithelial and stromal cells. In the malignant cores, only the tumoral glands were considered. Semi-quantitative analyses were performed by calculating histoscores (HS) as the product of the percentage stained cells $(0-100)$ and staining intensity $(0-3)$. If multiple staining intensities were present in the same core, the sum of the individual HS was taken to acquire the average HS of the entire core. Binary HS, with low and high expression respectively being defined as below and above the mean HS of 1.5 , were used for statistical analyses. Microvessel density (MVD) was determined by counting the number of CD31-positive blood vessels in each core.

\section{Statistical analysis}

The IBM/SPSS Statistics version 23/24 was used for statistical analyses. A Fisher's exact test was used to compare the binary Hh expression level in the benign and malignant tissue cores, and to evaluate any potential association between the protein expression levels in the tumor and the clinicopathological parameters. One-way ANOVA with contrast analysis was used to assess any potential correlation between MVD and clinicopathological factors.

The impact of the studied proteins and clinicopathological factors on time to BCR was determined by a logrank test and Kaplan-Meier analysis. A multivariate Cox proportional hazard regression model was used to determine the relative risk of important risk factors for BCR. Statistical results were considered significant at $p<0.05$.

\section{Results}

\section{PCa patient cohort characteristics}

The patient and tumor characteristics of the $170 \mathrm{PCa}$ patients are shown in Additional file 1: Table S1. The median age at the time of surgery was 61 years (range 45-71). Approximately two-thirds of patients had a pathological T stage $(\mathrm{pT}) \leq \mathrm{pT} 2 \mathrm{c}$, and only a small number of patients had a pathological $G S \geq 8$. Median followup was 8.4 years (range 1.1-13.7), and 23\% of patients developed biochemical recurrence (BCR) of PCa following radical surgery, as defined as a confirmed postoperative rise in PSA level to $>0.2 \mathrm{ng} / \mathrm{ml}$.

\section{Hh signaling in benign and cancerous prostate tissue}

Protein expression of the main Hh components in the $\mathrm{PCa}$ cores was compared with the expression level in the benign cores (Table 1 and Fig. 2). In general, Hh signaling protein expression was greater in the prostate epithelium than in the stromal tissue. When considering Hh signaling

Table $1 \mathrm{Hh}$ protein expression in benign and cancerous prostate tissue

\begin{tabular}{|c|c|c|c|c|c|}
\hline \multirow[b]{2}{*}{ Epithelial expression } & \multicolumn{2}{|c|}{ Benign prostate $(\mathrm{n})$} & \multicolumn{2}{|c|}{ Prostate cancer (n) } & \multirow{2}{*}{$\begin{array}{l}\text { Fisher's exact test }(2 \text {-sided }) \\
p \text {-value }\end{array}$} \\
\hline & Low (\%) & High (\%) & Low (\%) & High (\%) & \\
\hline $\mathrm{SHH}$ & $46(76.6)$ & $14(23.3)$ & $111(71.6)$ & $44(28.4)$ & 0.497 \\
\hline PTCH1 & $17(26.6)$ & $47(73.4)$ & $114(76)$ & $36(24)$ & $<0.001$ \\
\hline SMO & $3(4.7)$ & $61(95.3)$ & $5(3.2)$ & $150(96.8)$ & 0.695 \\
\hline SUFU & 19 (30.6) & $43(69.4)$ & $26(16.9)$ & $128(83.1)$ & 0.028 \\
\hline GLI1 & $44(73.3)$ & $16(26.7)$ & $130(83.9)$ & $25(16.1)$ & 0.061 \\
\hline GLI2 & $5(8.2)$ & $56(91.8)$ & $54(36.5)$ & $94(63.5)$ & $<0.001$ \\
\hline GLI3 & $18(29)$ & $44(71)$ & $85(55.2)$ & $69(44.8)$ & 0.001 \\
\hline Cyclin D1 & $54(93.1)$ & $4(6.9)$ & $94(61.4)$ & 59 (38.6) & $<0.001$ \\
\hline SNAIL & $24(39.3)$ & $37(60.7)$ & $31(20)$ & $124(80)$ & 0.005 \\
\hline SNAI3 & $59(95.2)$ & $3(4.8)$ & $134(86.5)$ & $21(13.5)$ & 0.092 \\
\hline \multicolumn{6}{|l|}{ Stromal expression } \\
\hline $\mathrm{SHH}$ & $65(100)$ & 0 & $153(100)$ & 0 & NA \\
\hline PTCH1 & $65(100)$ & 0 & $152(100)$ & 0 & NA \\
\hline SMO & $62(95.4)$ & $3(4.6)$ & $143(94.7)$ & $8(5.3)$ & 1.000 \\
\hline SUFU & $23(36.5)$ & $40(63.5)$ & $25(18.1)$ & $113(81.9)$ & 0.007 \\
\hline GLI1 & $58(93.5)$ & $46.5)$ & $141(91.6)$ & $13(8.4)$ & 0.783 \\
\hline GLI2 & 60 (93.8) & $4(6.3)$ & $136(95.1)$ & $7(4.9)$ & 0.741 \\
\hline GLI3 & 63 (98.4) & $1(1.6)$ & $146(98)$ & $3(2)$ & 1.000 \\
\hline
\end{tabular}

Statistical significant results are presented in Italic 


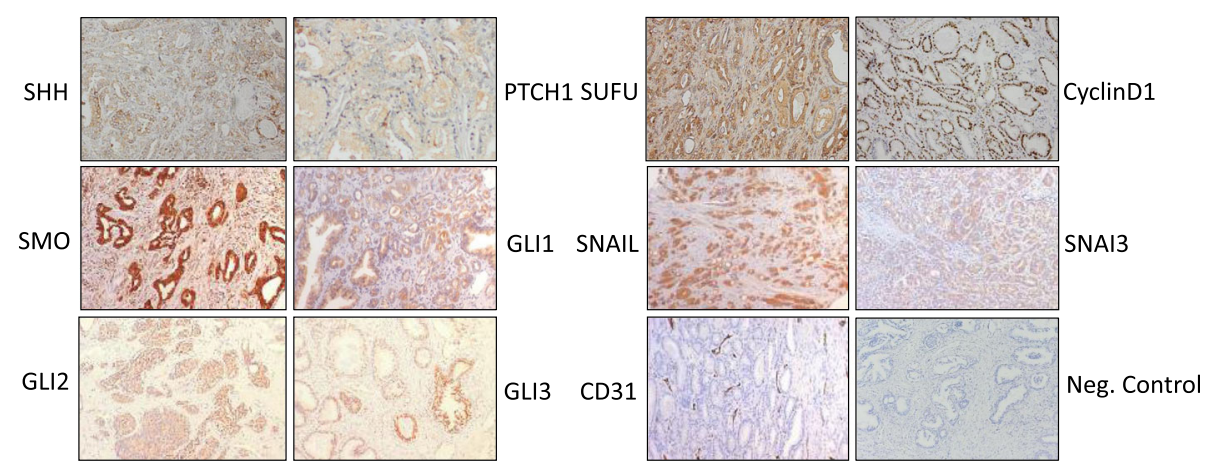

Fig. 2 Representative images of positive IHC staining in benign and malignant prostate tissue and a negative control

proteins in the epithelium, we observed that low levels of PTCH1 and GLI3 expression were more likely to occur in tumor tissue than in benign (PTCH1 76\% PCa versus $26.6 \%$ benign, and GLI3 $55.2 \%$ versus $29 \%$, respectively, $p<0.001)$.

In contrast, high expression of the SUFU negative Hh regulator was observed in both benign and malignant prostate epithelium, with significantly higher levels being seen in tumors $(p=0.028)$.. GLI2 was observed to be widely and highly expressed in both benign and malignant prostate tissues. High levels of Cyclin D1 were more commonly seen in $\mathrm{PCa}$ than in benign prostate epithelium $(p<0.001)$. High epithelial SNAIL expression was also mainly observed in PCa compared with benign prostate epithelium $(p=0.005)$. Few differences in $\mathrm{Hh}$ signaling protein expression levels were observed in the stromal compartments of benign and malignant prostate tissue, with only SUFU being more highly expressed in the stromal compartment of PCa tissue than in benign cores $(p<0.007)$.

\section{Correlation between Hh signaling proteins and clinicopathological factors}

We evaluated the clinical importance of $\mathrm{Hh}$ signaling protein expression in PCa patients. First, we investigated potential correlations between $\mathrm{Hh}$ protein expression and known prognostic clinicopathological factors such as pT stage, pathological GS, and surgical margin status. Higher epithelial GLI2 expression in the tumor was found to correlate with higher pathological GS $(p=0.047$, Table 2$)$, indicating that this might be a potential marker for aggressiveness in this PCa cohort. A trend was observed for higher epithelial GLI2 expression in tumors of a more advanced pT stage $(p=0.084)$.

We also observed a positive correlation between the mean vessel density (MVD) and pathological GS, suggesting that tumors with a more aggressive phenotype may present with a greater number of blood vessels (Fig. 3). The other Hh signaling proteins investigated did not demonstrate significant correlations with clinicopathological factors.

\section{Prognostic value of Hh signaling in prostate cancer}

Patients with a higher GS (pGS $\geq 7 ; p=0.023$ ), more advanced tumor stage (pT stage $>$ pT2c; $p<0.001$ ) and/or a positive surgical margin status $(p=0.004)$ had a shorter time to BCR where this occured. Higher epithelial GLI3 expression in the tumor showed a trend towards a better prognosis although this did not reach statistical significance in this cohort $(p=0.092)$ (Fig. 4).

In a multivariate Cox regression model, pT stage $(\mathrm{HR}=3.317 ; p=0.002)$, pathological GS $(\mathrm{HR}=2.572$; $p=0.4)$ and epithelial GLI3 expression ( $\mathrm{HR}=0.418$; $p=0.023)$ were each found to be significant predictors of BCR (Table 3).

\section{Discussion}

$\mathrm{PCa}$ is a heterogeneous disease with variable natural history, genetics, and treatment outcomes, and it is important to dissect the pathways that lead to its' progression. This is particularly important in cases of intermediaterisk $\mathrm{PCa}$, which will require the use of molecular tools in order to risk-stratify patients and better predict which men may have relatively indolent $\mathrm{PCa}$ which may not

Table 2 Correlation clinicopathological factors and epithelial GLI2 expression in the tumor

\begin{tabular}{|c|c|c|c|c|c|c|c|c|c|}
\hline \multirow[b]{2}{*}{ Fisher's exact test } & \multicolumn{3}{|c|}{ Pathological T stage (n) } & \multicolumn{3}{|c|}{ Pathological GS (n) } & \multicolumn{3}{|c|}{ Surgical margin (n) } \\
\hline & $\mathrm{pT} \leq 2(\%)$ & $\mathrm{pT}>2(\%)$ & $p$-value & $\mathrm{GS}<7(\%)$ & $\mathrm{GS} \geq 7(\%)$ & $p$-value & Negative (\%) & Positive (\%) & $p$-value \\
\hline Low epithelial GLI2 & $35(64.8)$ & $19(35.2)$ & 0.084 & $25(46.3)$ & $29(53.7)$ & 0.047 & $19(35.2)$ & $35(64.8)$ & 1.000 \\
\hline High epithelial GLI2 & $44(48.9)$ & $46(51.1)$ & & $26(28.9)$ & $64(71.1)$ & & $33(36.7)$ & $57(63.3)$ & \\
\hline
\end{tabular}

pT pathological T stage; GS Gleason Score

Statistical significant results are presented in Italic 


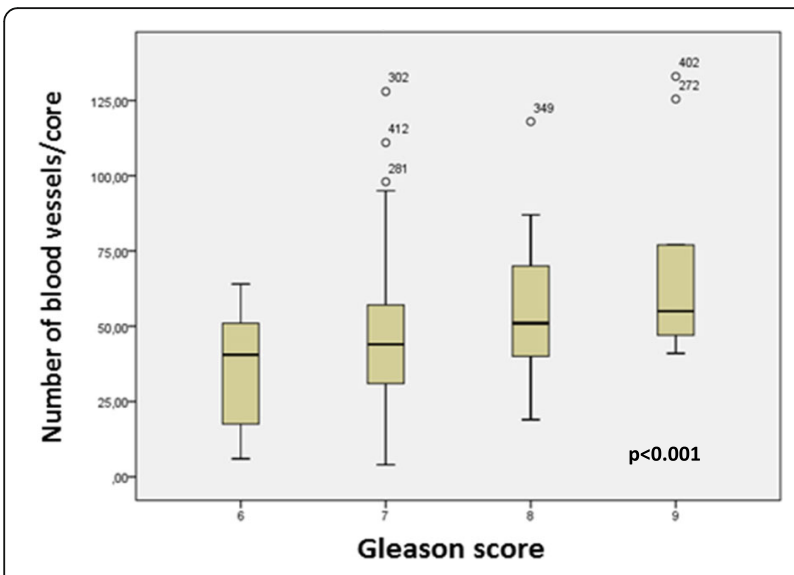

Fig. 3 Microvessel density as a function of pathological Gleason score

require immediate radical treatment with associated side-effects $[13,14]$. There is therefore an important unmet clinical need to establish robust molecular markers with which to accurately predict disease progression. The Hh signaling pathway has been implicated as being one of the pathways that drive the PCa progression to a more advanced disease state. In this retrospective study we compared the activation status of the Hh pathway between benign and malignant prostate tissue, and evaluated the clinical significance of $\mathrm{Hh}$ signaling in a PCa.

Previous reports have demonstrated active Hh signaling in PCa tissue, with higher levels of expression of several Hh pathway components in $\mathrm{PCa}$ compared with benign prostate tissue $[15,16]$. We similarly observed that Hh signaling appeared to be greater in malignant compared with benign prostate tissue, and in this cohort active Hh signaling status in PCa was mainly characterized by down-regulation of the PTCH1 and GLI3 negative regulators of this pathway. We also observed a
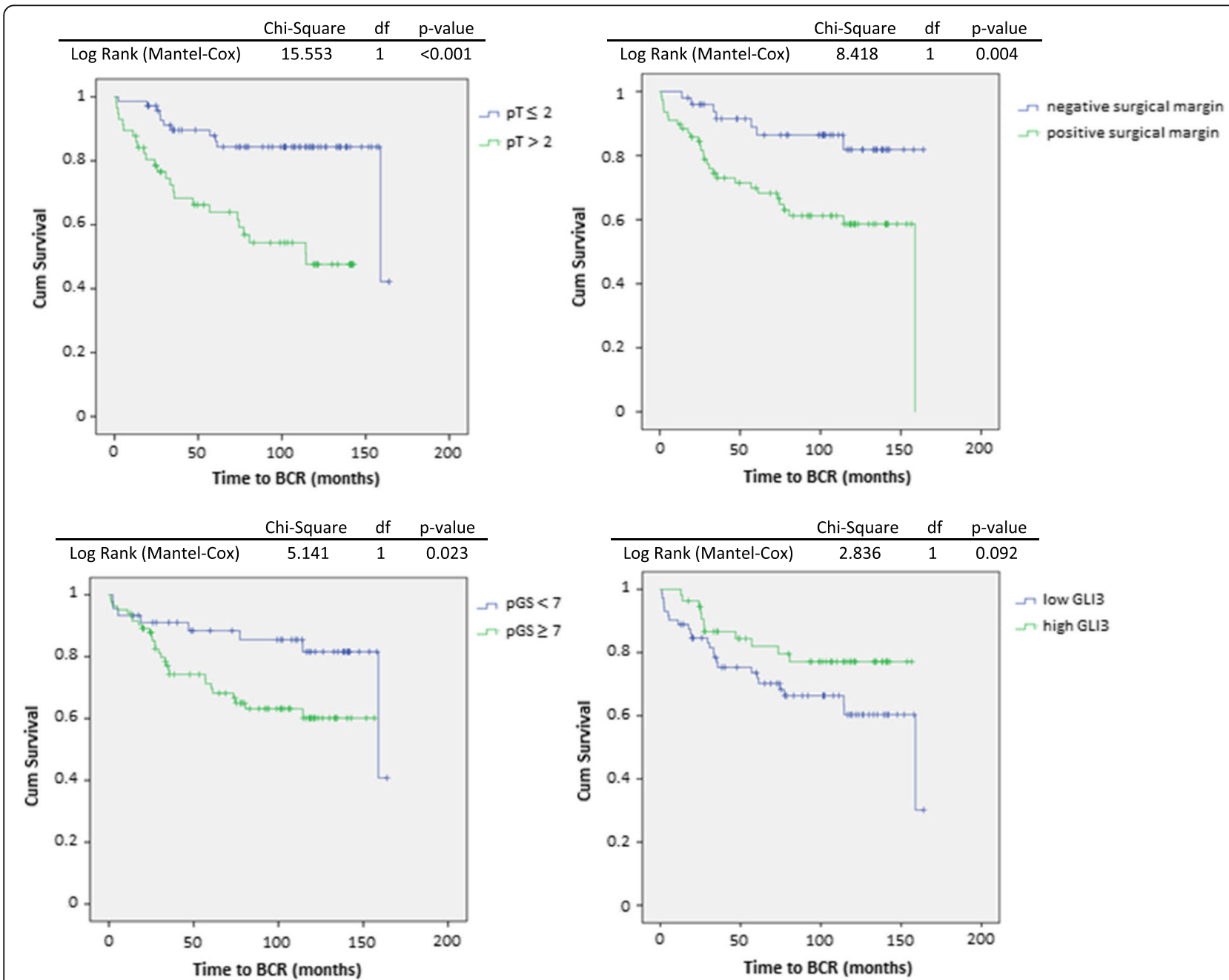

Fig. 4 Survival analyses and log rank test for time to BCR according to pT stage (upper left), pGS (lower left), surgical margin (upper right) and epithelial GLI3 expression in the tumor (lower right) 
Table 3 Multivariate Cox regression model for BCR

\begin{tabular}{llll}
\hline & Hazard Ratio & $95 \% \mathrm{Cl}$ & $p$-value \\
\hline pT stage & 3.317 & $1.562-7.045$ & 0.002 \\
Pathological GS & 2.572 & $1.042-6.346$ & 0.04 \\
Epithelial GLI3 & 0.418 & $0.197-0.885$ & 0.023
\end{tabular}

pT pathological T stage; GS Gleason score; Cl Confidence interval

positive correlation between high GLI2 expression in the tumor and a higher GS score, indicating that this might be a marker for an aggressive tumor phenotype. Narita et al. previously reported that GLI2 expression correlated with a more advanced PCa phenotype [17], whilst Kim et al. demonstrate correlations between Hh signaling molecules (GLI1, SHH, SMO, PTCH1) and GS score here, however in this latter study GLI2 expression was not assessed [18].

We observed that MVD was higher in PCa tumors with higher pathological GS score, indicating that more aggressive tumors have a greater degree of vascularization. This is consistent with a previous report by Erbersdobler et al. investigating a large PCa cohort [19], where MVD did not function as an independent prognostic marker, in line with our reported observations.

Our data demonstrated that $\mathrm{pT}$ stage and pathological GS are independent predictors of an adverse prognosis in terms of BCR following radical prostatectomy with curative intent. In addition, we demonstrate that epithelial GLI3 expression could represent a prognostic marker in surgical patients, with higher epithelial GLI3 expression reflecting a more favorable outcome. Other studies have previously suggested that the Hh signaling pathway might have a prognostic value in PCa $[18,20]$, and a study by McKee et al. demonstrated that $\mathrm{Hh}$ gene alterations are associated with an adverse prognosis in PCa patients [14].

\section{Conclusion}

It is a particular clinical challenge to tailor appropriate management of intermediate-risk $\mathrm{PCa}$, and there is only a limited number of clinically applicable biomarkers with which to risk-stratify these patients according to the potential indolent or aggressive nature of their disease. In this study, we demonstrated that active Hh signaling might reflect aggressive tumoral behavior, since high epithelial GLI2 expression positively correlates with a higher pathological GS. Moreover, higher epithelial GLI3 expression is an independent marker of a more favorable prognosis in this category of PCa cases.

\section{Additional file}

Additional file 1: Table S1. Patient and tumor characteristics of PCa patients $(n=170)$. (DOCX $13 \mathrm{~kb})$

\section{Abbreviations}

BCR: Biochemical recurrence; GLI: Glioma-associated oncogene; GS: Gleason score; GS: Gleason score; Hh: Hedgehog; HS: Histoscore; MVD: Microvessel density; PCa: Prostate cancer; PT: Pathological T stage; PTCH1: Patched 1; SHH: Sonic hedgehog; SMO: Smoothened; SUFU: Suppressor of fused; TMA: Tissue microarray

\section{Acknowledgements}

None.

\section{Funding}

AG and SI were sponsored by a grant from the National Cancer Plan Action 29 Belgium (KPC_29_023). KH is a clinical research fellow of the Research Foundation Flanders. Funding also came from the CIC of the MRC at University of Oxford and CRUK to CMM and RJM. RJB's research time was funded by the National Institute for Health Research, Cancer Research UK and Academy of Medical Sciences. CVs research time was funded by the National Institute for Health Research (NIHR) Oxford Biomedical Research Centre based at the Oxford University Hospitals NHS Trust and the University of Oxford. None of the funding bodies had any part in the design of the study and collection, analysis, and interpretation of data, or in writing the manuscript.

\section{Availability of data and materials}

The datasets used and/or analyzed during the current study are available from the corresponding author on reasonable request.

\section{Authors' contributions}

$\mathrm{SI}, \mathrm{CMM}, \mathrm{CV}, \mathrm{R} \mathrm{B}, \mathrm{EL}, \mathrm{RJ}$ and $\mathrm{KH}$ conceived and designed the study; CMM, CV, RJM and RJB constructed the TMAs; AG and SI performed the immunohistochemical stainings; SI, AG and EL assessed the scorings; CP and FU performed the statistical analyses; AG and SI wrote the paper. All authors have been involved in drafting the manuscript or revising it critically for important intellectual content and approved the final manuscript.

\section{Ethics approval and consent to participate}

TMA sections were obtained from the Oxford Centre for Histopathology Research, Oxford University Hospitals NHS Foundation Trust, Oxford, UK. The TMA contained patient samples from Oxford and was built under the approval of the Oxford Radcliffe Biobank Ethics Committee (reference number 09/H0606/5 + 5). The study itself was approved by the ethics committee of KU Leuven, Leuven, Belgium (reference number S55726). The requirement to obtain a written informed consent was waived because of the retrospective nature of this study and the fact that this research presented no risk of harm to subjects.

Consent for publication

Not applicable.

\section{Competing interests}

The authors declare that they have no competing interests.

\section{Publisher's Note}

Springer Nature remains neutral with regard to jurisdictional claims in published maps and institutional affiliations.

\section{Author details}

'Department of Oncology, Laboratory of Experimental Radiotherapy, KU Leuven - University of Leuven, KU Leuven Campus Gasthuisberg, Herestraat 49, box 815, 3000 Leuven, Belgium. ${ }^{2}$ Department of Radiation Oncology, University Hospitals Leuven, Leuven, Belgium. ${ }^{3}$ Department of Applied Mathematics, Royal Military Academy, Brussels, Belgium. ${ }^{4}$ Department of Oncology, CRUK/MRC Oxford Institute for Radiation Oncology, University of Oxford, Oxford, UK. ${ }^{5}$ Nuffield Department of Surgical Sciences, University of Oxford, John Radcliffe Hospital, Oxford, UK. ${ }^{6}$ Department of Pathology, University Hospitals Leuven, KU Leuven University of Leuven, Leuven, Belgium. 
Received: 17 January 2017 Accepted: 28 August 2017

Published online: 06 September 2017

\section{References}

1. Jiang J, Hui CC. Hedgehog signaling in development and cancer. Dev Cell. 2008;15(6):801-12.

2. Karhadkar SS, Bova GS, Abdallah N, Dhara S, Gardner D, Maitra A, Isaacs JT, Berman DM, Beachy PA. Hedgehog signalling in prostate regeneration, neoplasia and metastasis. Nature. 2004;431(7009):707-12.

3. Freestone SH, Marker P, Grace OC, Tomlinson DC, Cunha GR, Harnden P, Thomson AA. Sonic hedgehog regulates prostatic growth and epithelial differentiation. Dev Biol. 2003;264(2):352-62.

4. Beachy PA, Karhadkar SS, Berman DM. Tissue repair and stem cell renewal in carcinogenesis. Nature. 2004;432(7015):324-31.

5. Gonnissen A, Isebaert S, Haustermans K. Hedgehog signaling in prostate cancer and its therapeutic implication. Int J Mol Sci. 2013;14(7):13979-4007.

6. Kogerman P, Grimm T, Kogerman L, Krause D, Unden AB, Sandstedt B, Toftgard R, Zaphiropoulos PG. Mammalian suppressor-of-fused modulates nuclear-cytoplasmic shuttling of Gli-1. Nat Cell Biol. 1999;1(5):312-9.

7. Humke EW, Dorn KV, Milenkovic L, Scott MP, Rohatgi R. The output of hedgehog signaling is controlled by the dynamic association between suppressor of fused and the Gli proteins. Genes Dev. 2010;24(7):670-82.

8. Wang B, Fallon JF, Beachy PA. Hedgehog-regulated processing of Gli3 produces an anterior/posterior repressor gradient in the developing vertebrate limb. Cell. 2000;100(4):423-34.

9. Pan $Y$, Bai $C B$, Joyner $A L$, Wang B. Sonic hedgehog signaling regulates $G$ li2 transcriptional activity by suppressing its processing and degradation. Mol Cell Biol. 2006;26(9):3365-77.

10. Sasaki H, Nishizaki Y, Hui C, Nakafuku M, Kondoh H. Regulation of Gli2 and Gli3 activities by an amino-terminal repression domain: implication of Gli2 and Gli3 as primary mediators of Shh signaling. Development. 1999;126(17): 3915-24.

11. Reese AC, Cooperberg MR, Carroll PR. Minimal impact of clinical stage on prostate cancer prognosis among contemporary patients with clinically localized disease. J Urol. 2010;184(1):114-9.

12. Stark JR, Perner S, Stampfer MJ, Sinnott JA, Finn S, Eisenstein AS, Ma J, Fiorentino M, Kurth T, Loda M, Giovannucci EL, Rubin MA, Mucci LA. Gleason score and lethal prostate cancer: does $3+4=4+3$ ? J Clin Oncol. 2009;27(21):3459-64.

13. Ishkanian AS, Mallof CA, Ho J, Meng A, Albert M, Syed A, van der Kwast T, Milosevic M, Yoshimoto M, Squire JA, Lam WL, Bristow RG. High-resolution array $\mathrm{CGH}$ identifies novel regions of genomic alteration in intermediate-risk prostate cancer. Prostate. 2009;69(10):1091-100.

14. McKee CM, Xu D, Cao Y, Kabraji S, Allen D, Kersemans V, Beech J, Smart S, Hamdy F, Ishkanian A, Sykes J, Pintile M, Milosevic M, van der Kwast T, Zafarana G, Ramnarine VR, Jurisica I, Mallof C, Lam W, Bristow RG, Muschel RJ. Protease nexin 1 inhibits hedgehog signaling in prostate adenocarcinoma. J Clin Invest. 2012:122(11):4025-36.

15. Tzelepi V, Karlou M, Wen S, Hoang A, Logothetis C, Troncoso P, Efstathiou E. Expression of hedgehog pathway components in prostate carcinoma microenvironment: shifting the balance towards autocrine signalling. Histopathology. 2011;58(7):1037-47.

16. Sanchez $P$, Hernandez AM, Stecca B, Kahler AJ, DeGueme AM, Barrett A, Beyna M, Datta MW, Datta S, Altaba A. Inhibition of prostate cancer proliferation by interference with SONIC HEDGEHOG-GLI1 signaling. Proc Natl Acad Sci U S A. 2004;101(34):12561-6.

17. Narita S, So A, Ettinger S, Hayashi N, Muramaki M, Fazli L, Kim Y, Gleave ME. GLI2 knockdown using an antisense oligonucleotide induces apoptosis and chemosensitizes cells to paclitaxel in androgen-independent prostate cancer. Clin Cancer Res. 2008;14(18):5769-77.

18. Kim TJ, Lee JY, Hwang TK, Kang CS, Choi YJ. Hedgehog signaling protein expression and its association with prognostic parameters in prostate cancer: a retrospective study from the view point of new 2010 anatomic stage/ prognostic groups. J Surg Oncol. 2011;104(5):472-9.

19. Erbersdobler A, Isbarn H, Dix K, Steiner I, Schlomm T, Mirlacher M, Sauter G, Haese A. Prognostic value of microvessel density in prostate cancer: a tissue microarray study. World J Urol. 2010;28(6):687-92.

20. Azoulay S, Terry S, Chimingqi M, Sirab N, Faucon H, de MS GD, Moutereau S, Maille P, Soyeux P, Abbou C, Salomon L, Vacherot F, de La TA, Loric S, Allory Y. Comparative expression of hedgehog ligands at different stages of prostate carcinoma progression. J Pathol. 2008;216(4):460-70.

\section{Submit your next manuscript to BioMed Central and we will help you at every step:}

- We accept pre-submission inquiries

- Our selector tool helps you to find the most relevant journal

- We provide round the clock customer support

- Convenient online submission

- Thorough peer review

- Inclusion in PubMed and all major indexing services

- Maximum visibility for your research

Submit your manuscript at www.biomedcentral.com/submit
) Biomed Central 